\title{
Creative Parameters for Adult Active Web Users
}

\section{Параметры креативности у взрослых активных web-пользователей}

\author{
Elena Medvedskaia \\ Ph.D. in Psychology, Assistant Professor, Brest State
} A. S. Pushkin University, Brest (the Republic of Belarus)

ORCID ID: https://orcid.org/0000-0003-2033-510X

Researcher ID: M-4006-2019

E-mail: EMedvedskaja@mail.ru

\section{Елена Медведская}

Кандидат психологических наук, доцент, Брестский государственный университет имени А. С. Пушкина, г. Брест (Республика Беларусь)

\section{ABSTRACT}

The aim of the article is to analyze empirical data that test the hypothesis of greater creativity of active Internet users compared to adult fans of traditional reading.

Methods. The study was conducted on a statistically large and homogeneous sample by age, level of education and professional activity (the sphere of mental work). The differentiation of respondents into groups for comparative analysis was carried out on the basis of two criteria: 1) the choice of information system in free time (book or Internet); 2) the time allocated to work with the specified system. The criteria were determined through anonymous and voluntary questionnaires. The parameters of creativity were measured for different types of creativity: verbal (Mednik's test in the adaptation of A. A. Voronin) and figurative (Sievert's test).

Address for correspondence, e-mail: kpnu_lab_ps@ukr.net Copyright: (C) Medvedskaia Elena

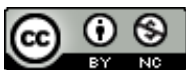
The article is licensed under CC BY-NC 4.0 International (https://creativecommons.org/licenses/by-nc/4.0/)

(C) Medvedskaia Elena

DOI (article): https://doi.org/10.32626/2227-6246.2020-49.224-243 
The research presents the results of the comparative analysis conducted in two contrasting groups that select different information systems: subjects of reading and active web users. Statistically significant advantages of reading subjects in the expression of most of the measured parameters of both verbal (uniqueness and number of responses) and figurative (uniqueness and number of associations from remote areas) creativity were established.

Conclusions. It is empirically proved that there are significantly more creative people among fans of traditional printed books. This demonstrates that the technical capabilities of the Internet (the richness of content, the possibility of free choice of content and participation in its creation, etc.) do not automatically provide conditions for the display of creative abilities of users. An explanation is offered for the lower creativity of adult active web users through the specifics of the media image as the main unit of encoding information in digital media (the iconic nature of information and the suggestiveness of impact).

Key words: sign system, printed word, media image, verbal creativity, visual creativity.

\section{Введение}

Способность к творческой деятельности, итогом которой является создание некоторого нового (объективно или субъективно) продукта, выступает одной из атрибутивных характеристик человека. И более чем полувековая история конструирования искусственного интеллекта, несмотря на очень впечатляющие успехи в данной области, показывает, что «...XXI век распрощался с иллюзией подобия искусственного и естественного интеллекта: машинные программы не моделируют структуру и механизмы деятельности человеческого разума, а моделируют лишь конечные результаты его работы (например, решение задач), они подобны естественному интеллекту лишь функционально...» (Катречко, 2016: 304). Другими словами, тест Тьюринга искусственный интеллект выполнит, но безусловной прерогативой человека продолжают оставаться как обнаружение проблем, так и поиск новых путей их решения.

В силу своей особой значимости структура и детерминация творческих способностей постоянно находилась в поле

(C) Medvedskaia Elena

DOI (article): https://doi.org/10.32626/2227-6246.2020-49.224-243 
зрения исследователей. С 50-х гг. ХХ в. благодаря работе Дж. Гилфорда в обиходе психологической науки и практики прочно закрепились понятия креативности и дивергентного мышления, которое является продуктивным, предполагающим варьирование способов решения проблемы, приводящим к неожиданным выводам и результатам (Guilford, $1958,1959)$. В концепции М. А. Холодной, одной из наиболее авторитетных на постсоветском пространстве, в широком смысле креативность трактуется как творческие интеллектуальные способности, в узком смысле - как способность порождать множество оригинальных идей и использовать нестандартные способы интеллектуальной деятельности в нерегламентированных условиях деятельности или как дивергентное мышление - интеллектуальные способности, проявляющиеся в готовности выдвигать множество правильных идей относительно одного и того же объекта (Холодная, 2004). В настоящее время в психологии существуют различные теоретические подходы к пониманию креативности, детальное изложение которых и их критический анализ содержатся в целом ряде фундаментальных работ (Богоявленская, 2002; Холодная, 2004; Sternberg \& Davidson, 1986 и др.). Несмотря на разные методологические основания, на которых обосновываются и разные параметры креативности, большинство современных ученых склонны к синонимичности употребления понятий «креативность» и «творческие способности», которые обобщенно трактуются как способности к нахождению оригинальных решений и нестандартных способов деятельности в неопределенных условиях.

Следует также отметить, что социальная ценность творческих способностей только возрастает в современном динамичном и высокотехнологичном мире. Произошедшая буквально в течение последнего десятилетия цифровая революция существенно изменяет различные традиционные виды деятельности человека (общение, игра, труд, отдых и т. п.). В концепции дигимодернизма английского культуролога (C) Medvedskaia Elena

DOI (article): https://doi.org/10.32626/2227-6246.2020-49.224-243 
A. Кирби (Kirby, 2009) оцифровывание рассматривается как доминирующий вектор развития общества. Для его характеристики ученый использует метафору силового поля, тем самым акцентируя, что это только иная форма, трансформация в которую в принципе не порождает некоторого нового содержания. Но, продолжая метафору А. Кирби, можно говорить о том, что это мощное силовое поле постепенно затягивает в свою орбиту не только культурные достижения предшествующих эпох, оно, безусловно, относится и к человеку как творцу этих самых достижений.

Оценки воздействия новых (цифровых) медиа на творческие способности их пользователей разными специалистами неоднозначны. В качестве позитивного аспекта отмечается, в частности, создание условий для проявления пользователями собственной активности, например: «Гипертекстовость и интерактивность онлайн-медиа... создает совершенно иной формат потребления информационного контента медиа - это своеобразное «путешествие» по контенту, где каждый обладает не только возможностью продолжать его до бесконечности, но и правом мгновенно, прямо по ходу «путешествия» создавать, изменять или публично обсуждать его» (Киреев, 2010: 117). Относительно последствий этой активности высказываются также и негативные мнения. Российский философ В. В. Миронов, анализируя использование потенциала интерактивности Web 2.0, обращается к идеям М. Бахтина о карнавале как о временно санкционированном, дозированном господстве низовой культуры. Благодаря новым техническим возможностям карнавал становится постоянным: «Коммуникационные средства диалога превращаются в его сущность, которая очень хорошо выражается принципом «не важно, о чем говорить, главное говорить»... Это приводит к тому, что главным становится не качество продукта творчества, а систематичность и способы его распространения. В этих условиях возникает феномен поп-культуры -

(C) Medvedskaia Elena

DOI (article): https://doi.org/10.32626/2227-6246.2020-49.224-243 
доминирование низовой культуры в глобальном масштабе» (Миронов, 2017: 34-35).

Открытость интернет-пространства и интерактивность новых медиа обеспечивают их пользователям свободу выбора, свободу мысли и творчества: «В наши дни интернет-пространство открывает новые возможности для перехода от репродуктивного мышления («мыслить - значит вспоминать») к продуктивному (порождать самостоятельные критические суждения)» (Гусельцева, 2018: 136). Благодаря этим новым возможностям «возникает новая среда, в которой мы сейчас живем и незаметно меняемся. С одной стороны, жить становится лучше. Например, Интернет появился, теперь можно как бы преодолевать пространство и время, получить доступ к самым разным информационным ресурсам. Но, с другой стороны, легкая возможность получать готовую информацию отрицательно влияет на культивирование творческих способностей» (Лекторский, 2017: 144). Некоторые специалисты отстаивают иную позицию: поскольку устройства становятся все более «умными», то можно говорить уже об интеллектуальном партнерстве человека и машины (Голубинская, 2015). Особенно это партнерство проявляется в творческих процессах, ведь даже самые простые поисковые действия типа введения запросов уже изменяют виртуальную среду (как минимум посредством рекламы, реагирующей на ранее запрашиваемый пользователем контент).

Представленные мнения авторитетных ученых в характеристике позитивных и негативных последствий новых медиа для становления творческих способностей их пользователей диаметрально отличаются. Однако данных эмпирических исследований, посвященных обсуждаемой проблеме, в соответствующей литературе не обнаружено. Поэтому целью настоящего исследования является проверка гипотезы о большей креативности активных пользователей цифровых технологий, по сравнению с ценителями традиционного чтения.

(C) Medvedskaia Elena

DOI (article): https://doi.org/10.32626/2227-6246.2020-49.224-243 


\section{Задача статьи}

В статье представлен сравнительный анализ параметров креативности (вербальной и образной) у взрослых, отдающих свои предпочтения разным типам знаковых систем традиционной вербальной и современной цифровой.

\section{Методы и методики исследования}

В исследовании (добровольно и анонимно) принимало участие 600 респондентов в возрасте от 35 до 58 лет, среди которых 380 женщин и 220 мужчин. Все участники исследования имеют высшее образование и являются работниками умственного труда (педагоги, медики, экономисты, юристы). Таким образом, обобщенно выборку можно охарактеризовать как выборку работников умственного труда, завершивших основные этапы своей социализации в социокультурной ситуации, которую можно назвать доцифровой эпохой. Сбор данных осуществлялся на протяжении 20182019 гг.

Общая выборка была дифференцирована на две группы на основании анонимного анкетирования, направленного на выявление ведущей для респондентов знаковой системы информации и ежедневных привычек обращения к различным носителям информации. Отнесение субъекта в группу осуществлялось при совпадении двух критериев:

1) однозначный выбор ведущей знаковой системы в свободное время (Интернет или традиционная книга);

2) большая часть свободного времени, уделяемая деятельности с этой системой.

Обработка данных анкетирования показала, что в исследованной выборке только 17\% респондентов (102 человека) остаются сторонниками традиционной книги как носителя информации. Представители данной группы выбирают чтение по разным причинам (развивает мышление и памлть, обогащает словарный запас, увлекает и др.), указывая не только на физический дискомфорт у экрана (устают глаза,

(C) Medvedskaia Elena

DOI (article): https://doi.org/10.32626/2227-6246.2020-49.224-243 
укачивает), но и на худшее усвоение информации. В дальнейшем данная группа будет обозначаться как «субъекты читающие» .

35\% (204 опрошенных) отдают свой выбор новым медиа, который они аргументируют большей доступностью содержания, его компактностью, «сжатостью» изложения материала и отмечают при обращении к книге необходимость сосредоточения, сложности поиска информации, переживания скуки или тревоги. При последующем обсуждении представители этой группы будут фиксироваться как «активные web-пользователи» .

Большую часть выборки, как и следовало ожидать, представляют респонденты, не имеющие каких-либо однозначных приоритетов в выборе источников информации. Это люди, которые с легкостью и удовольствием как читают книги, так и пользуются цифровыми носителями. Для осуществления заявленного сравнительного анализа методом контрастных групп результаты измерения креативности у представителей данного типа исключены для обработки и обсуждения.

Креативность является предметом теоретического изучения с разных методологических позиций, что приводит и к разнообразию методического инструментария ее эмпирического измерения. Недостатки существующих диагностических методик креативности (тесты Гилфорда, Торренса, Медника и др.) неоднократно становились предметом критического анализа (Холодная, 2004; Sternberg \& Davidson, 1986 и др.) по двум ведущим основаниям, а именно ограничение понимания креативности как дивергентного мышления (и, соответственно, актуализация тестовыми инструкциями у испытуемых именно интеллектуальных, а не творческих усилий) и принятие уникальности (или редкости ответов) за ведущий критерий креативности. Таким образом, в настоящее время вопрос о валидности тестов креативности продолжает оставаться дискуссионным.

(C) Medvedskaia Elena

DOI (article): https://doi.org/10.32626/2227-6246.2020-49.224-243 
Поскольку в разных системах кодирования информации используются и разные единицы (слово и медиаобраз), то возникает необходимость одновременной проверки и разных видов креативности (вербальной и образной). Эта необходимость диктует сопоставимость параметров креативности, измеряемых посредством разных методик. С учетом указанного требования в настоящем исследовании были использованы тест вербальной креативности С. Медника и тест образной креативности З. Зиверт.

Используемый для измерения вербальной креативности тест C. Медника (RAT) (Дружинин, 1999: 322-346) адаптирован А. А. Ворониным (лаборатория психологии способностей Института психологии РАН) и в русскоязычной версии известен как тест речемыслительной креативности (РМК) (Воронин, 1994: 40-81). Тест основывается на «принципе омонима». Во взрослом варианте испытуемому предлагаются триады слов (20), представляющих отдаленные друг от друга ассоциативные области. Задача заключается в установлении между ними ассоциативной связи, т. е. поиске слова, объединяющего заданные таким образом, чтобы с каждым из них оно образовало некие осмысленные словосочетания. Время выполнения теста не ограничено (занимает в среднем порядка 20-35 минут).

Автор теста понимает под вербальной креативностью способность к рекомбинированию элементов ситуации. По его мнению, конвергентная и дивергентная составляющие одновременно присутствуют в творческом процессе: чем более отдалены по смыслу элементы, используемые для решения проблемы, тем креативнее этот процесс. Предусмотрено, что каждая из триад имеет некое слово-стереотип, сочетающееся с ними. Например, на триаду «случайная - гора долгожданная» стереотипным ответом будет «встреча», на триаду «дверь - доверие - быстро» - ответ «входить» и др.

Тест позволяет измерить три параметра вербальной креативности: уникальность (способность человека к созданию (c) Medvedskaia Elena DOI (article): https://doi.org/10.32626/2227-6246.2020-49.224-243 
нового); оригинальность (нестандартность ответов, рассчитываемая для каждого испытуемого отдельно по специальной формуле) и количество ответов (степень продуктивности и работоспособности). Данная методика считается «наиболее адаптированным к нашим условиям тестом креативности" (Дружинин, 1999: 196), несмотря на наличие определенных моментов для ее критики (навязанность ситуации тестирования, отсутствие свободы выбора материала, отождествление креативности с оригинальностью и уникальностью вербальной продукции).

Для изучения невербальной креативности был использован тест «Свобода ассоциаций» 3. Зиверт, позволяющий определять визуальную креативность, способность к преобразованиям (гипотетичность и вариативность мышления) (Ильин, 2009: 326-330). Стимульный материал представляет собой 15 рисунков современного российского художника А. Н. Фанталова. Задача респондентов - дать рисунку несколько интерпретаций. Время выполнения теста не ограничивается (как правило, тоже занимает порядка получаса).

Тест позволяет определить несколько параметров креативности: количество вариантов (ассоциаций); уникальность (или оригинальность) ответов; разнообразие стратегий (ассоциативные зоны) и степень отдаленности ассоциаций. Таким образом, измеряемые в данном тесте параметры частично могут быть сопоставлены с параметрами вербальной креативности теста С. Медника.

Поскольку психометрических данных к тесту свободных ассоциаций в русскоязычной литературе не обнаружено, то проводились подсчеты общего числа ассоциаций (в том числе и отдельно числа ассоциаций, представляющих отдаленные ассоциативные зоны). Расчеты ведущего параметра креативности - оригинальности ответов - осуществлялись по принятым в других тестах креативности алгоритмам, а именно по оценке статистической редкости ответа в исследуемой выборке $(\mathrm{n}=100)$ : повторяющиеся ответы - 0 баллов, (c) Medvedskaia Elena

DOI (article): https://doi.org/10.32626/2227-6246.2020-49.224-243 
уникальные - 1 балл. При этом повторяющимися считались ответы из близких ассоциативных областей. Например, к рисунку 13 в 0 баллов оценивались следующие варианты: «Воздушный шар», «Воздушный шар над морем», «Воздушный шар летит над землей», «Полет на воздушном шаре» . Аналогичным образом обозначались и другие родственные ассоциации к обсуждаемому рисунку («Подводный мир», «Подводное царство», «Водный мир», «Морская жизнь»).

Дальнейший анализ параметров вербальной и невербальной креативности осуществлялся отдельно в пяти случайных комбинациях респондентов для двух контрастных групп: «субъектов читающих" $(\mathrm{n}=20)$ и «активных webпользователей» $(\mathrm{n}=20)$. Такое численное ограничение выборок обусловлено ограничениями математико-статистических критериев, используемых для оценки достоверности возможных различий измеряемых параметров креативности. Необходимо отметить, что для всех пяти рандомизированных последовательностей получены идентичные результаты. Поэтому обсуждение представляется целесообразным ограничить материалом одной из групп.

\section{Результаты и дискуссии}

Сравнительный анализ паралетров вербальной креативности

Усредненные по выборкам результаты измерения вербальной креативности отражены в табл. 1, в которой буквами обозначены соответствующие параметры креативности: У - уникальность; О - оригинальность; К - количество ответов.

Таблица 1

Показатели теста вербальной креативности C. Медника (RAT)

\begin{tabular}{|c|c|c|c|c|c|}
\hline \multicolumn{2}{|c|}{ Субъекты читающие } & \multicolumn{3}{c|}{ Активные web-пользователи } \\
\hline $\mathbf{y}$ & $\mathbf{0}$ & $\mathbf{K}$ & $\mathbf{y}$ & $\mathbf{0}$ & $\mathbf{K}$ \\
\hline 9,75 & 0,62 & 24 & 4,45 & 0,48 & 17,85 \\
\hline
\end{tabular}

(C) Medvedskaia Elena

DOI (article): https://doi.org/10.32626/2227-6246.2020-49.224-243 
Представленные в табл. 1 данные свидетельствуют, что все параметры вербальной креативности (уникальность, оригинальность и количество ответов) выше у представителей группы «субъекты читающие».

Качественный анализ ответов показал, что у них присутствует не только умение подбирать ассоциации, но и стремление выйти за рамки инструкции и соединить тестовые триады в более сложные, чем слово-ассоциация, вербальные конструкции. Например: на триаду «воздух - быстрая свежая» респонденты отвечают словосочетаниями (свежее утро, струя воды), на триаду «народная - страх - мировая» следует ответ «трагические события» или еще более сложная ассоциация «Вставай, страна огромная» (вместо ответа «война», который, как самый популярный, имеет нулевой коэффициент оригинальности); на триаду «садовая - мозг пустая» следует целое умозаключение: «И в пустом мозгу может расти сад из цветущих деревьев», а на триаду «поезд - купить - бумажный» ответ представляет воспоминание-фантазию: «В детстве я могла купить билет на бумажный поезд и уехать на нем далеко-далеко». Подобные тенденции к самостоятельному усложнению конструкций отсутствовали в контрастной группе активных web-пользователей.

Применение критерия Розенбаума доказало достоверность выявленных различий по таким двум параметрам вербальной креативности, как:

1) уникальность $\left(\mathrm{Q}=10\right.$ при $\mathrm{Q}_{\text {крит }}=9$ для $\left.\mathrm{p}<0,01\right)$;

2) количество ответов $\left(\mathrm{Q}=8\right.$ при $\mathrm{Q}_{\text {крит }}=7$ для $\left.\mathrm{p}<0,05\right)$.

По параметру оригинальности значимые отличия между респондентами разных групп отсутствуют $(\mathrm{Q}=3)$, что может быть обусловлено спецификой выборки, на которой А. А. Воронин осуществлял психометрические расчеты (молодые менеджеры, возраст до 35 лет). Кроме того, сам автор адаптации теста считает более значимым показателем вербальной креативности именно уникальность ответов (Воронин, 1994: 55).

(C) Medvedskaia Elena

DOI (article): https://doi.org/10.32626/2227-6246.2020-49.224-243 
DOI: https://doi.org/10.32626/2227-6246.2020-49 2020. випуск 49

Сравнительный анализ паралетров визуальной креативности

При качественном анализе первичных протоколов обращает на себя внимание наличие не только ассоциаций-номинаций, но и полноценных предложений. Например, первый рисунок из стимульного набора (рис. 1).

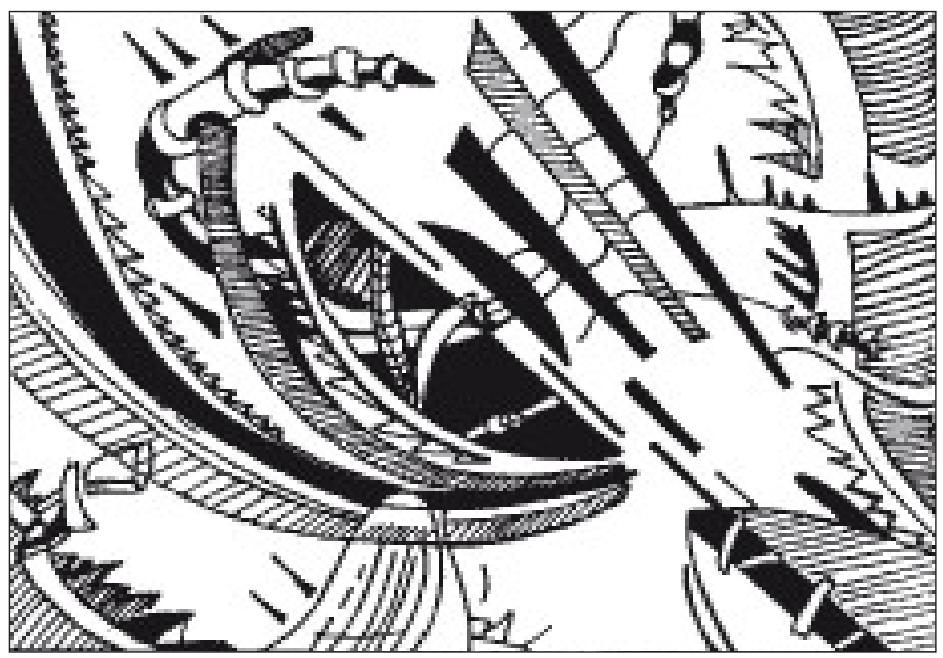

Puc. 1. Материал из стимульного набора теста образных ассоциаций

Наряду с ассоциациями-существительными («космический корабль», «крушение корабля», «напряжение», «вид местности сверху» и др.) были даны следующие варианты ответов: «Пила что-то разрезает», «Скорпион, прорывающийся сквозь песчаную бурю», «В море разбивается лодка на щепки» и др. Такие же, фактически сюжетные, зарисовки присутствовали у участников исследования в ассоциациях по всему стимульному материалу теста.

В проективном тесте Роршаха подобные ответы выделяются в отдельную категорию «движение», наличие которой свидетельствует о воображении и фантазии (Анастази \& (C) Medvedskaia Elena

DOI (article): https://doi.org/10.32626/2227-6246.2020-49.224-243 
DOI: https://doi.org/10.32626/2227-6246.2020-49

2020. випуск 49

Урбина, 2003: 453). Наличие данной категории выступает показателем гибкости и разносторонности ассоциативного процесса, инициативности ассоциативной деятельности. Поэтому дополнительно проводились также подсчеты и ассоциаций данного типа.

В табл. 2 представлены усредненные для представителей разных групп параметры, которые имеют следующие буквенные обозначения: У - уникальность (оригинальность); К - количество ответов; ОтА - отдаленность ассоциаций; Дв - движение.

таблица 2

Параметры образной креативности

\begin{tabular}{|c|c|c|c|c|c|c|c|}
\hline \multicolumn{3}{|c|}{ Субъекты читающие } & \multicolumn{4}{|c|}{ Активные web-пользователи } \\
\hline $\mathbf{y}$ & $\mathbf{K}$ & ОтА & Дв & $\mathbf{y}$ & $\mathbf{K}$ & ОтА & Дв \\
\hline 15,26 & 27,13 & 7,33 & 2,13 & 10,73 & 21,46 & 4,33 & 0,6 \\
\hline
\end{tabular}

Данные табл. 2 демонстрируют, что все параметры невербальной креативности выше в группе, предпочитающей вербальную систему кодирования информации. Применение критерия Розенбаума для оценки достоверности выявленных различий показало следующее:

- для уникальности ассоциаций: $\mathrm{Q}=8$ при $\mathrm{Q}_{\text {крит }}=6$ для $\mathrm{p}<0,05$

- для количества ответов: $\mathrm{Q}=4(\mathrm{Q}>0,05)$;

- для числа ассоциаций из отдаленных областей: $\mathrm{Q}=9$ при $\mathrm{Q}_{\text {крит }}=9$ для $\mathrm{p}<0,01$;

- для ответов категории «движение»: $\mathrm{Q}=6$ при $\mathrm{Q}_{\text {крит }}=6$ для $\mathrm{p}<0,05$.

Статистические расчеты позволяют утверждать, что только по одному параметру - количество ассоциаций представители разных выборок не отличаются друг от друга. По всем другим (нетипичность ответов, активность ассоциативного процесса, богатство воображения) достоверные преимущества выявлены у любителей традиционного чтения.

(C) Medvedskaia Elena

DOI (article): https://doi.org/10.32626/2227-6246.2020-49.224-243 
Таким образом, полученные данные противоречат прогнозируемому у активных пользователей цифровых технологий росту творческих способностей.

\section{Заключение}

Многогранность и трудноуловимость природы креативности обусловливает несовершенство существующих психологических инструментов ее изучения, в том числе и тестов, посредством которых «можно выделить креативов, но нельзя определить точно некреативов» (Ильин, 2009: 196). Полученные данные с определенной оговоркой позволяют утверждать, что креативов однозначно больше среди любителей чтения, чем среди взрослых, отдающих предпочтение цифровым технологиям. Сравнительный анализ выраженности параметров креативности показал, что представители выборки «субъектов читающих" являются статистически более креативными и более работоспособными, чем представители группы «активных web-пользователей» (для вербальной креативности) и достоверно отличаются от них большей уникальностью ответов и большей широтой ассоциативного процесса (для визуальной креативности).

Полученные данные на первый взгляд могут показаться очевидными (особенно для параметров вербальной креативности), без учета возраста респондентов. Все они нормативно завершили основные циклы психического и личностного развития еще в доцифровом обществе. Это позволяет говорить о том, что новые медиа обеспечивают благоприятные возможности (свобода выбора контента, диалогичность и др.) для развития творчества как одного из высших видов активности человека, но реализует эти возможности конкретный человек. Как демонстрируют эмпирические данные, стихийное взаимодействие с цифровыми технологиями (несмотря на наличие у них развивающего потенциала) не обеспечивает спонтанного развития креативности.

(c) Medvedskaia Elena

DOI (article): https://doi.org/10.32626/2227-6246.2020-49.224-243 
Думается, что обозначенный парадокс (условия есть, но они не работают) объясняется такими атрибутами медиаобраза, как иконичность передаваемой информации и, соответственно, суггестивность ее воздействия. Если все дано глазам, то пользователю необходимо ставить дополнительные, специальные цели по осмыслению, дополнению, изменению воспринимаемой «картинки». Но кто это делает, заглядывая в Интернет просмотреть... И совершенно не случайно в повседневном обиходе закрепился именно этот термин («просмотреть», «смотреть») даже для такой познавательной деятельности в сети, как поиск информации. Поэтому внешняя свобода Интернета в выборе информации имеет и существенное внутреннее ограничение для ее обработки (в том числе и творческой) реципиентом, обусловленное медиаобразом как основной единицей кодировки информации.

\section{Литература}

Анастази А., Урбина С. Психологическое тестирование. Санкт-Петербург : Питер, 2003. 688 с.

Богоявленская Д. Б. Психология творческих способностей. Москва : Академия, 2002. 320 c.

Воронин А. Н., Галкин Т. В. Диагностика вербальной креативности (адаптация теста Медника). Методы психологической диагностики. Москва : Ин-т психологии РАН, 1994. Вып. 2. С. 40-81.

Голубинская А. В. Нейрокогнитивный подход к исследованию поколения Z. International Journal of Humanities and Natural Science. 2015. Vol. 1. P. 161-167.

Гусельцева М. С. Информационная социализация в транзитивном обществе: контексты дигимодернизма. Цифровое общество как культурный контекст развития человека: сб. науч. $\mathrm{cm}$. и материалов междунар. конф. (Коломна, 14-17 февр. 2018 г.). Коломна : Гос. соц.-гуманитар. ун-т, 2018. С. 135-141.

Дружинин В. Н. Психология общих способностей. Санкт-Петербург : Питер, 1999. 368 с.

Ильин Е. П. Психология творчества, креативности, одаренности. Санкт-Петербург : Питер, 2009. 434 с.

Катречко С. Л. О соотношении искусственного и естественного интеллекта. Философия искусственного интеллекта: науч. тр. Всерос.

(C) Medvedskaia Elena

DOI (article): https://doi.org/10.32626/2227-6246.2020-49.224-243 
межәисциплинар. конф. (Москва, 16-17 марта 2016 г.). Москва : ИИнтелл, 2017. С. 304-319.

Киреев П. С. Новые медиа в современном информационно-коммуникационном пространстве. Социология. 2010. № 2. С. 115-127.

Лекторский В. А. Философия, искусственный интеллект, когнитивные исследования. Философия искусственного интеллекта: науч. тр. Всерос. междисииплинар. конф. (Москва, 17-18 марта 2016 г.). Москва : ИИнтелл, 2017. С. 37-44.

Миронов В. В. Трансформация культур: от классической к электронной. Философия искусственного интеллекта: науч. тр. Всерос. междисииплинар. конф. (Москва, 17-18 марта 2016 г.). Москва : ИИнтелл, 2017. С. 28-36.

Холодная М. А. Когнитивные стили. О природе индивидуального ума. Санкт-Петербург : Питер, 2004. 384 с.

Guilford, J. P. (1958). New frontiers of testing in the discovery and development of human talent. Seventh Annual Western Regional Conference on Testing Problems. Los Angeles. P. 20-32.

Guilford, J. P. (1959). Three faces of intellect. American Psychologist, 14, 469-479.

Kirby, A. (2009). Digimodernism: How New Technologies Dismantle the Postmodern and Reconfigure Our Culture. New York : Continuum Publishing Corporation.

Sternberg, R. J., \& Davidson, J. E. (1986). Conceptions of giftedness: A map of the terrain. In R. J. Sternberg, J. E. Davidson (Eds.) Conceptions of giftedness. New York : Cambridge University Press. P. 3-18.

\section{References}

Anastazi, A., \& Urbina, S. (2003). Psikhologicheskoie testirovaniie [Psychological testing]. Sankt-Peterburg : Piter [in Russian].

Bogoiavlenskaia, D. B. (2002). Psikhologiia tvorcheskikh sposobnostei [Psychology of Creativity]. Moskva : Akademiia [in Russian].

Voronin, A. N., \& Galkina, T. V. (1994). Diagnostika verbalnoi kreativnosti (adaptatsiia testa Mednika) [Diagnostics of verbal creativity (adaptation of the Mednik's test)]. Metody psikhologicheskoi diagnostiki - Methods of psychological diagnosis, 2, 40-81. Moskva : In-t psikhologii RAN [in Russian].

Golubinskaia, A. V. (2015). Neirokognitivnyi podkhod k issledovaniiu pokoleniia Z [Neurocognitive approach to the study of generation Z]. International Journal of Humanities and Natural Science, 1, 161167 [in Russian].

(C) Medvedskaia Elena

DOI (article): https://doi.org/10.32626/2227-6246.2020-49.224-243 
Guseltseva, M. S. (2018). Informatsionnaia sotsializatsiia v tranzitivnom obshchestve: konteksty digimodernizma [Informational Socialization in a Transitive Society: The Contexts of Digimodernism]. Tsifrovoie obshchestvo kak kulturnyi kontekst razvitiia cheloveka - Digital society as a cultural context for human development: Proceedings of the International Conference, (pp. 135-141). Kolomna : Gos. sots.-gumanitar. un-t [in Russian].

Druzhinin, V. N. (1999). Psikhologiia obshchikh sposobnostei [Psychology of General Abilities]. Sankt-Peterburg : Piter [in Russian].

Ilin, E. P. (2009). Psikhologiia tvorchestva, kreativnosti, odarennosti [Psychology of creativity, giftedness]. Sankt-Peterburg [in Russian].

Katrechko, S. L. (2017). O sootnoshenii iskusstvennogo i estestvennogo intellekta [On the ratio of artificial and natural intelligence]. Filosofiia iskusstvennogo intellekta - Philosophy of Artificial Intelligence: Proceedings of all-Russian Interdisciplinary Conference, (pp. 304-319). Moskva : IIntell [in Russian].

Kireiev, P. S. (2010). Novyie media v sovremennom informatsionno-kommunikatsionnom prostranstve [New media in the modern information and communication space. Sotsiologiia - Sociology, 2, 115-127 [in Russian].

Lektorskii, V. A. (2017). Filosofiia, iskusstvennyi intellekt, kognitivnyie issledovaniia [Philosophy, Artificial Intelligence, Cognitive Research]. Filosofiia iskusstvennogo intellekta - Philosophy of Artificial Intelligence: Proceedings of all-Russian Interdisciplinary Conference, (pp. 37-44). Moskva : IIntell [in Russian].

Mironov, V. V. (2017). Transformatsiia kultur: ot klassicheskoi k elektronnoi [Transformation of cultures: from classical to electronic]. Filosofiia iskusstvennogo intellekta - Philosophy of Artificial Intelligence: Proceedings of all-Russian Interdisciplinary Conference, (pp. 37-44). Moskva : IIntell [in Russian].

Kholodnaia, M. A. (2004). Kognitivnyie stili. O prirode individualnogo uma [Cognitive styles. About the nature of the individual mind]. Sankt-Peterburg : Piter [in Russian].

Guilford, J. P. (1958). New frontiers of testing in the discovery and development of human talent. Seventh Annual Western Regional Conference on Testing Problems, (pp. 20-32). Los Angeles.

Guilford, J. P. (1959). Three faces of intellect. American Psychologist, 14, $469-479$.

Kirby, A. (2009). Digimodernism: How New Technologies Dismantle the Postmodern and Reconfigure Our Culture. New York : Continuum Publishing Corporation.

(C) Medvedskaia Elena

DOI (article): https://doi.org/10.32626/2227-6246.2020-49.224-243 
Sternberg, R. J., \& Davidson, J. E. (1986). Conceptions of giftedness: A map of the terrain. In R. J. Sternberg, J. E. Davidson (Eds.). Conceptions of giftedness, (pp. 3-18). New York : Cambridge University Press.

\section{Медведская Елена. Параметры креативности у взрослых активных wеb-пользователей}

\section{АННОТАЦИЯ}

Цель статьи заключается в анализе эмпирических данных, проверяющих гипотезу о больщей креативности активных интернет-пользователей, по сравнению со взрослыми любителями традиционного чтения.

Методы. Исследование проводилось на статистически большой и гомогенной выборке по возрасту, уровню образования и профессиональной деятельности (сферы умственного труда). Дифференциация респондентов на группы для проведения сравнительного анализа осуществлялась на основании двух критериев: 1) выбор информационной системы в свободное время (книга или Интернет); 2) время, отводимое работе с указанной системой. Критерии определялись посредством анонимного и добровольного анкетирования. Измерение параметров креативности осуществлялось для разных ее видов: вербальной (тест C. Медника в адаптации А. А. Воронина) и образной (тест 3. Зиверт).

Результаты исследования. Представлены результаты сравнительного анализа, проведенного в двух контрастных группах, выбирающих различные информационные системы: "субъектов читающих»и «активных шеb-пользователей». Установлены статистически значимые преимущества у субъектов читающих в выраженности большинства измеренных параметров как вербальной (уникальность и количество ответов), так и образной (уникальность и число ассоциаций из отдаленных областей) креативности.

Вывод. Эмпирически доказано, что креативов достоверно больше среди любителей традиционной печатной книги. Это демонстрирует, что технические возможности Интернета (богатство содержания, возможности свободного выбора контента и участия в его создании и др.) автоматически не обеспечивают условий для проявления творческих способностей пользователей. Предложено объяснение меньшей креативности взрослых активных шеb-пользователей в связи со спе-

(C) Medvedskaia Elena

DOI (article): https://doi.org/10.32626/2227-6246.2020-49.224-243 
DOI: https://doi.org/10.32626/2227-6246.2020-49 2020. ВиПУСК 49

цификой медиаобраза как основной единицы кодирования информации в цифровых медиа (иконический характер информации и суггестивность воздействия).

Ключевые слова: знаковая система, печатное слово, медиаобраз, вербальная креативность, визуальная креативность.

\section{Медведська Олена. Параметри креативності у дорослих активних web-користувачів}

\section{АНОТАЦІЯ}

Мета статmі полягає в аналізі емпіричних даних, що перевіряють гіпотезу про більшу креативність активних інтернет-користувачів, порівняно з дорослими любителями традиційного читання.

Методи. Дослідження проводилося на статистично великій і гомогенній вибірці за віком, рівнем освіти та професійною діяльністю (сфери розумової праці). Диреренціація респондентів на групи для проведення порівняльного аналізу здійснювалася на підставі двох критеріїв: 1) вибір інформаційної системи у вільний час (книга або Інтернет); 2) час, що відводиться роботі із зазначеною системою. Критерії визначалися за допомогою анонімного і добровільного анкетування. Вимірювання параметрів креативності здійснювалося для різних ї̈ видів: вербальної (тест C. Медника в адаптації А. А. Вороніна) й образної (тест 3. Зіверт).

Результати дослідження. Представлені результати порівняльного аналізу, проведеного у двох контрастних групах, які вибирають різні інформаційні системи: "суб'єктів читаючих» $i$ "активних web-користувачів». Установлено статистично значущі переваги у суб'єктів читаючих у вираженості більшості вимірюваних параметрів як вербальної (унікальність і кількість відповідей), так і образної (унікальність і число асоціацій із віддалених срер) креативності.

Висновок. Емпірично доведено, що креативів достовірно більше серед любителів традиційної друкованої книги. Це демонструє, що технічні можливості Інтернету (багатство змісту, можливості вільного вибору контенту й участі в його створенні тощо) автоматично не забезпечують умов для прояву творчих здібностей користувачів. Запропоновано пояснення меншої креативності дорослих активних wеb-користувачів у зв'язку зі специфікою медіаобразу як основної одиниці кодування інфор(C) Medvedskaia Elena

DOI (article): https://doi.org/10.32626/2227-6246.2020-49.224-243 
ISSN 2227-6246 (Print)

ISSN 2663-6956 (Online)

ПРОБЛЕМИ СУЧАСНОї ПСИХОЛОГІї

DOI: https://doi.org/10.32626/2227-6246.2020-49

2020. ВИПУСК 49

мації в цифрових медіа (іконічний характер інформації та сугестивність впливу).

Ключові слова: знакова система, друковане слово, медіаобраз, вербальна креативність, візуальна креативність.

Original manuscript received May 03, 2020

Revised manuscript accepted June 10, 2020

(C) Medvedskaia Elena

DOI (article): https://doi.org/10.32626/2227-6246.2020-49.224-243 